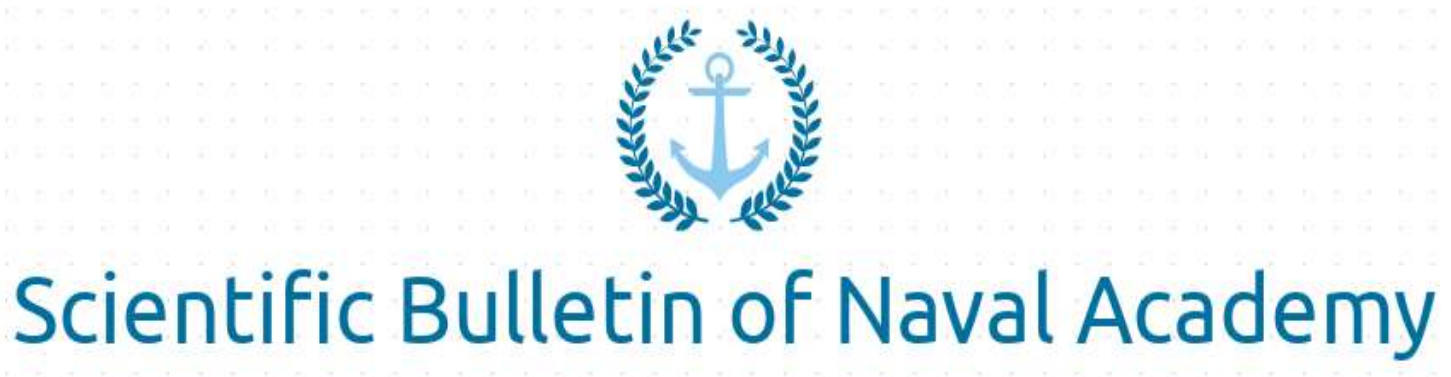

SBNA PAPER • OPEN ACCESS

Analysis the quality indicators of electricity and of the equipment used in the navigation boat

To cite this article: B Asalomia, Scientific Bulletin of Naval Academy, Vol. XXIII 2020, pg.251-259.

Available online at www.anmb.ro

ISSN: 2392-8956; ISSN-L: 1454-864X

doi: $10.21279 / 1454-864 X-20-12-102$

SBNA@ 2020. This work is licensed under the CC BY-NC-SA 4.0 License 


\title{
Analysis the quality indicators of electricity and of the equipment used in the navigation boat
}

\author{
B Asalomia ${ }^{1}$ G Samoilescu ${ }^{2}$ \\ ${ }^{1}$ CLC Eng.; Northern Marine Management, ; Military Technical Academy, București \\ ${ }^{2} \mathrm{PhD}$. Professor, Department of Electrical Engineering and Naval Electronics, Faculty \\ of Marine Engineering, "Mircea cel Batran" Naval Academy, Str. Fulgerului, 900218, \\ Constanta, Romania \\ Email: asalomiabogdan@yahoo.com;gheorghe.samoilescu@anmb.ro,
}

\begin{abstract}
The paper analyzes the navigation equipment according to the electricity consumption and its quality. Are analyzed: Integrated management systems; Algorithm for the implementation of the Energy Management System; Naval energy management system; Ways of achieving energy efficiency in the ship's electrical system. A research study is being carried out in the field of ship transport and in the development of energy naval energy systems and the improvement of the energy efficiency of the ships.
\end{abstract}

\section{Introduction}

Maritime transport is the backbone of today's global economy, as $90 \%$ of global commercial transactions are carried by sea. Much of our lifestyle today is influenced by the existence of maritime transport as a cheap and reliable means of transport worldwide.

The contribution of maritime transport to global warming, although relatively small today, in terms of harmful emissions, has already been established and for transport to be part of a sustainable economy it will have to reduce greenhouse gas emissions.

The increase of the energy efficiency on board the ships allows to reduce the consumption of fuel and therefore the emissions of carbon dioxide. In the last years we have witnessed an intensification of research efforts to increase the energy efficiency of the ships, which vary from improving the existing components to developing new solutions $[1,2,3]$.

This paper aims to contribute with a different vision regarding the electrical equipment in the navigation cabin and its influence on the energy balance of the shipping vessel. This approach places particular emphasis on the system requirements generated by the interactions between parts of the equipment seen from the point of view of the deck officer found in the navigation booth.

The modelling options related to on-board electrical equipment vary depending on the type of energy system used and the scope of their functionality [4,5]. The energetic analysis is done with the aim of applying a more structured and systematic approach towards the ship's systems with an emphasis on their energy performance. This analysis must be made for the purpose of understanding and saving electricity consumed by navigation equipment and other related equipment that may influence the energy balance of the ship. It plays a very important part regarding the final operating costs of the ship [6,7]. 
The analysis leads to a better supervision of the automated naval installations, the equipping of the synoptic naval panels with electrical and electronic elements of signaling and warning.The analysis leads to a better check of the operation made by the indicators for the naval electromechanical installations in the deck compartment and the navigation cabin $[8,9]$.

\section{The integrated navigation system found in the navigation cabin}

The integrated navigation system on the ship's control deck, the Integrated Bridge System (IBS) gives the watch officer centralized access to all navigation sensors and alarms related to ship safety $[10,11,12,13,14,15]$. The IBS system also offers the possibility of increasing efficiency in making a faster decision, reducing the risk of human error to near zero. A typical IBS is connected and receives real-time information with other electrical equipment in the navigation cabin and other compartments 16,17,18]. These equipment are: gyro compass, magnetic compass, ECDIS equipment, ultrasound probe, DGPS (Differential Global Positioning System), radar equipment, BNWAS (Bridge Navigational Watch \& Alarm System) motion sensors, GMDSS (Global Maritime Distress and Safety System) ), AIS (Automatic Identification System). The main advantage of IBS is that it can seamlessly integrate several sensors on one common platform. All sensors are interfaced with each other with the processing units known as Data Acquisition Units (DAUs). DAU has the ability to gather all the data and then redirects it to MFC's (Multi-Function Console) or MFD's (Multi-Function Display) displays.Other equipment that contributes to the good functionality of the Integrated Navigation System are [19,20,21,22]:

Auto Power Management System - Systems - Auto Power Management System (APMS) can be integrated with the main board or, if needed, can be supplied separately in an independent console.

1. The automatic mode of APMS systems consists of:

- Lack of the intervention of an operator

- Automatic selection of standby generators (standby)

- Auto start / synchronization of standby DG (diesel generator)

- Self charging with consumers

- Auto unloading (removal from the system) of non-essential consumers and automatic shutdown if necessary.

2. Auto-assisted - The automatic assistance system consists of:

- Prompt information of the operator in case of need for manual start-up for starting the standby generator (idle)

- Automatic synchronization of the generator when entering the system

- Automatic dosing of consumers' tasks

3. APMS has the following functionalities:

- Generator Protection

- Remote DG Start / Stop

- Load Dependent Start / Stop

- Heavy Consumer Block Logic

- Auto Load Shedding, Active \& Reactive Load Sharing

- Low Load Shut Down, High Load Call Up

- Black Out Recovery

- Event Logging

- Fault/Alarm History

Trending

Integrated Platform Management System Today's modern ships have the capabilities of automating 
the integrated system platform, which allows them to reach unprecedented levels of system survival and operational efficiency. The integration of these systems on board ships can optimize the operational capacity of the interconnected equipment. The main location of the IPMS is in the engine control room and the secondary location is on the bridge. Moreover, the control and monitoring system is also feasible on other independent consoles. IPMS is also interfaced with the Auto Power Management system and shares data with the IBS system. [23;24].

Automatic Date Acquisition System The automatic data acquisition system (ADAS) is the naval version of an alarm monitoring system. ADAS can be used as a system for monitoring gas turbines, the main monitoring system of the ship's engine. [2.3]

Degaussing System Such a system is required on board ships because a ship is a huge magnet due to its permanent magnetism (acquired since the construction phase) and induced magnetism (due to the cut of the Earth's magnetic field at the time of navigation). Demagnetization (degaussing) is a process to continuously demagnetize a ship. Also this system is present and highly developed in military ships which, if not demagnetized, would be permanently threatened by underwater mines, torpedoes and other magneto-sensitive artillery equipment. [23;24]

\section{ECDIS (Electronic Chart Display and Information System)}

Electronic Chart Display and Information System is designed and built to meet the most stringent requirements imposed by exploitation in the marine environment $[14,15]$-figure 1,2 .

The FMD-3000 series for ECDIS is the product of a long experience in the field, of FURUNO, namely experience in computer technology and electronics of navalized equipment. For the ECDIS FMD model FURUNO came with a new technology based on the display of electronic charts, navigation lines, also having the possibility to receive other navigation data or information, from the various navigation equipment in the control room. All information being displayed on a 19-inch highresolution (FMD-3200) or 23.1-inch (FMD-3300) screen. The ECDIS - FMD-3200-BB is delivered without a monitor, allowing the user to choose the variant he wants [25].

Ships, from the point of view of cyber security, are becoming more and more secure and in some cases the tendency is for the cyber threat of electronic naval equipment to be close to zero. This threat in the naval field, where the ship, when moving at sea, becomes an isolated system and in some cases vulnerable is a risk worth considering. This risk can have quite serious consequences both economically for the maritime industry and financially for the shipowner.

Cyber security is a problem that is beginning to be seen very seriously on board, in order to deal with this growing threat. Fortunately, more and more information is emerging to help all interested parties understand the challenges that the digital age is facing. In this sense, awareness campaigns about the consequences generated by this present-day danger take place regularly.

In this respect, certain routine procedures based on cyber security have been developed on board ships, procedures aimed at preventing cyber threats and removing them before they become a problem. Awareness of staff, crew members and officers operating electronic equipment on board, from the point of view of cyber security, is the first step in ensuring a safe climate regarding electronic equipment being operated on board ships. The training of the officers assigned to operate these equipment are certainly the first steps towards a safer future from this point of view at sea. According to the latest security policies implemented on board ships, all USB (Universal Serial Bus) ports are blocked, with access only guaranteed by the Commander's consent. Being part of the list of critical equipment on board the ship ECDIS equipment is doubled, and the backup system is also completely isolated from the first ECDIS equipment, updating them individually. Automatic synchronization is not recommended. The memory sticks are supplemented by the company and are used on board only for updating electronic maps, being specially dedicated to this. After they are scanned and checked for 
viruses they can be inserted into the system.

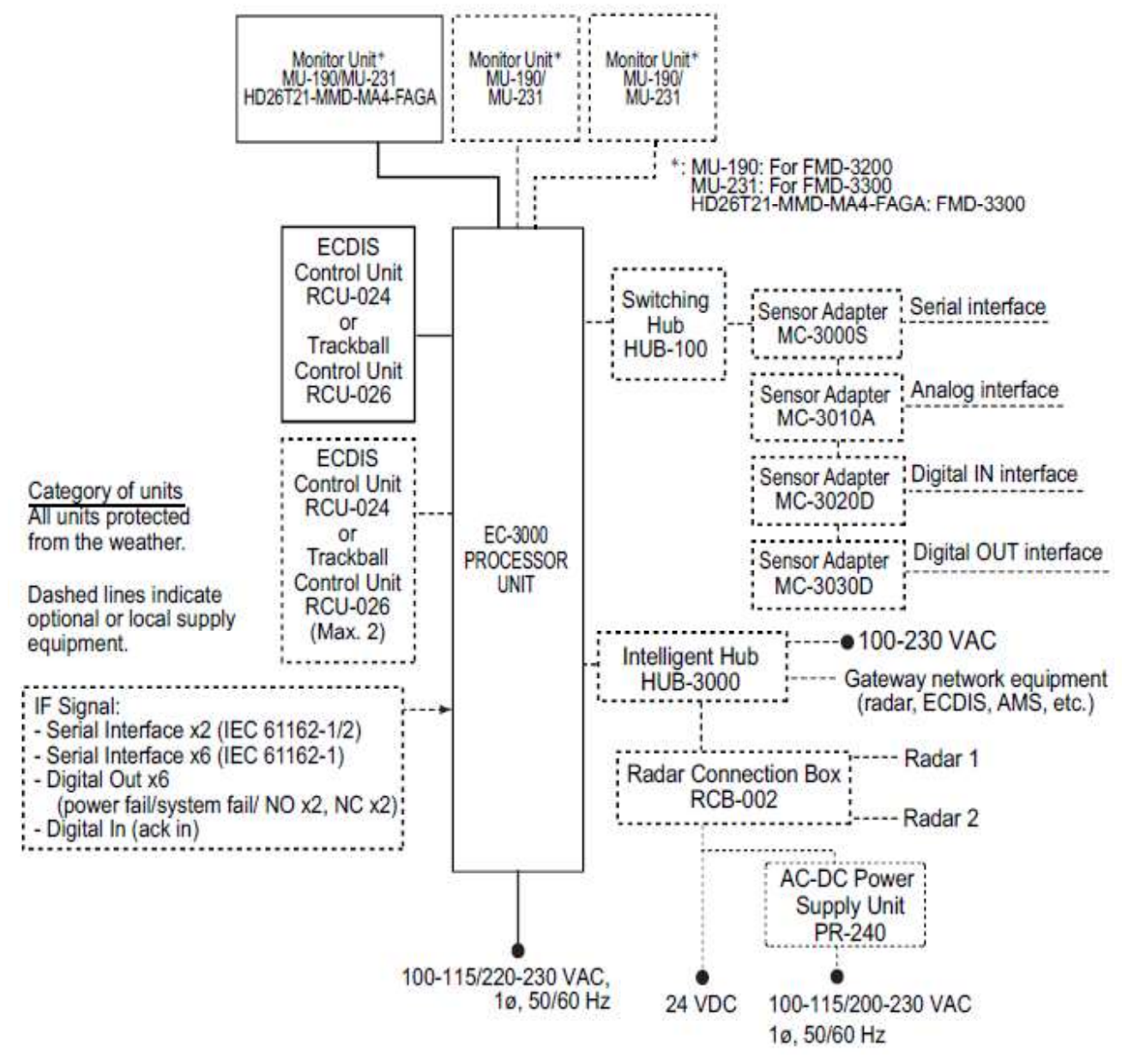

Fig. 1.System Configuration - ECDIS. Multiple working system.

According to the company policy and internal procedures, all the equipment (Memory Flash / Hard drive, is stored and is in the custody of the Commander and the Chief of Mechanics. The company policy regarding cyber security is periodically revised at an interval not exceeding 12 months. [20;21; 22].

Among the numerous equipment in the navigation cabin, whose systems and software must be constantly updated, are the ECDIS (Electronic Chart Display and Information System), an integral part of Bridge Integrate System (BIS). In order to make all these updates safe, a risk assessment is carried out by the navigating officer. All activities performed in the navigation booth as well as the data provided by each equipment are permanently monitored. ECDIS equipment is included in this category. , and all settings and operations that take place are recorded, and the records are kept according to company policy. This monitoring now includes the measures taken on board the ship to avoid cyber threats to all networked equipment, including ECDIS equipment. To assist officers aboard the ship for such monitoring, the international fora, including the United Kingdom Hydrographic Office (UKHO), have approved the publication of supporting documents that have been included in publications such as NP133C, located at aboard ships, which contains sections on ECDIS. These sections cover how to maintain, collect information and manage cyber risk. Checklists have been developed that help the officer in charge of the navigation to perform a risk assessment realistically 
when performing an ECDIS equipment upgrade. These lists help the officer in charge to keep accurate records and of the steps he has taken in accordance with their company's cyber security procedures and policies.

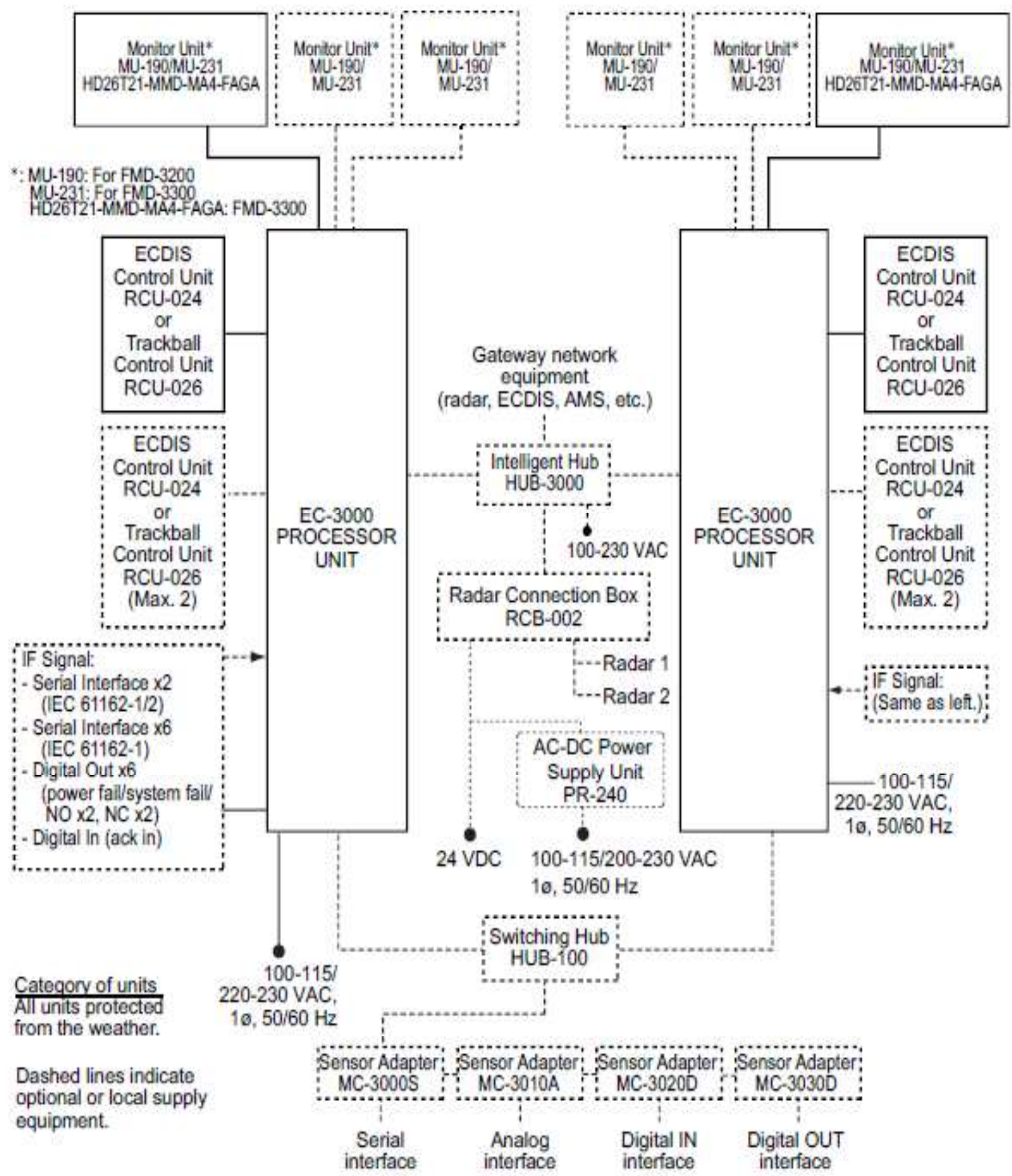

Fig. .2 ECDIS Equipment - Control Unit - RCU-024

Thus, these checklists present the steps that the navigation officer must follow when making updates to the electronic equipment in the navigation booth. [26]

In conclusion, the familiarization and training of the crew, of the officers designated to operate the ship's electronic equipment is essential for the computerized vessels where all the equipment is 
integrated / interconnected between them. In order to operate modern, safe and efficient computerized ships, crew training sessions on cyber security threats should become standard practice, as part of a ship's routine. $[18 ; 19]$

\section{Optimization of the information path}

After all intermediate waypoints (WP) are inserted, the route can be optimized from the existing settings in ECDIS (Electronic Chart Display and Information System). If no optimization strategy is chosen, then the optimization is done with "Max speed" the maximum speed, defined by the parameters of the ship. In the end, the optimization calculates all the parameters for the steering direction (course, the distance between two intermediate points, the start of the rotation maneuver, etc.). [22;25]. From this point of view we can speak of four optimization methods:

-Max speed It uses the maximum speed of the ship as it is set in the initial data of the ship in the calculation method, and multiplies it with all the factors that can reduce this speed, such as: weather conditions, ice zones, water friction ie resistance to advancement. In addition, the speed limitation, where there is an intermediate point of navigation for navigation and thus can be generated, calculates the ETA (Estimated Time of Arrival) ie the estimated time of arrival of the ship to the destination. This is also calculated based on the Estimated Time of Departure (ETD) ie the estimated time for departure of the ship from the port as well as the maximum speed of movement of the ship. [2. 3]

-Timetable It is calculated using the required speed of the ship so that it reaches the final destination at the required date and time. In this case the maximum speed of the ship is never exceeded. The officer enters the estimated time of departure of the ship (ETD) and the estimated time of arrival of the ship to its destination (ETA), to calculate the speed required for the ship to travel the respective distance. [2.3]

-Max.profit This is calculated based on the estimated time for departure of the port (ETD). In this calculation are taken into account: the cost of fuel and the fixed cost necessary for the ship to reach the final destination. Thus, the best speed of the ship is calculated which must be taken into account in order to obtain maximum profit per unit of time. [23; 25]

-Min. cost

It is based on Estimated Time of Departure (ETD), and this calculation takes into account the cost of fuel and the fixed cost of operating the ship, thus calculating the speed that must be used during navigation in order to obtain a minimum total cost. The user (the officer) must set the cost parameters in advance to use this feature-Table 1.2. [25]

Table 1. Cost values according to speed, at different points of the trip

\begin{tabular}{|c|c|c|c|c|}
\hline WPT & Min. cost & Max. profit & Timetable & Max. speed \\
\hline 1 & 4.8 & 10.9 & 10.0 & 10 \\
\hline 2 & 4.8 & 12.9 & 15.0 & 15 \\
\hline 3 & 4.8 & 12.9 & 16.2 & 20 \\
\hline 4 & 4.8 & 12.9 & 16.2 & 20 \\
\hline 5 & 6.0 & 12.9 & 15.0 & 15 \\
\hline 6 & 6.0 & 12.9 & 16.2 & 20 \\
\hline 7 & 4.8 & 12.9 & 16.2 & 20 \\
\hline 8 & 4.8 & 12.9 & 16.2 & 20 \\
\hline 9 & 6.0 & 12.9 & 16.2 & 17 \\
\hline 10 & 4.8 & 8.0 & 8.0 & 8 \\
\hline
\end{tabular}


Table 2. Fuel consumption as a function of ship speed

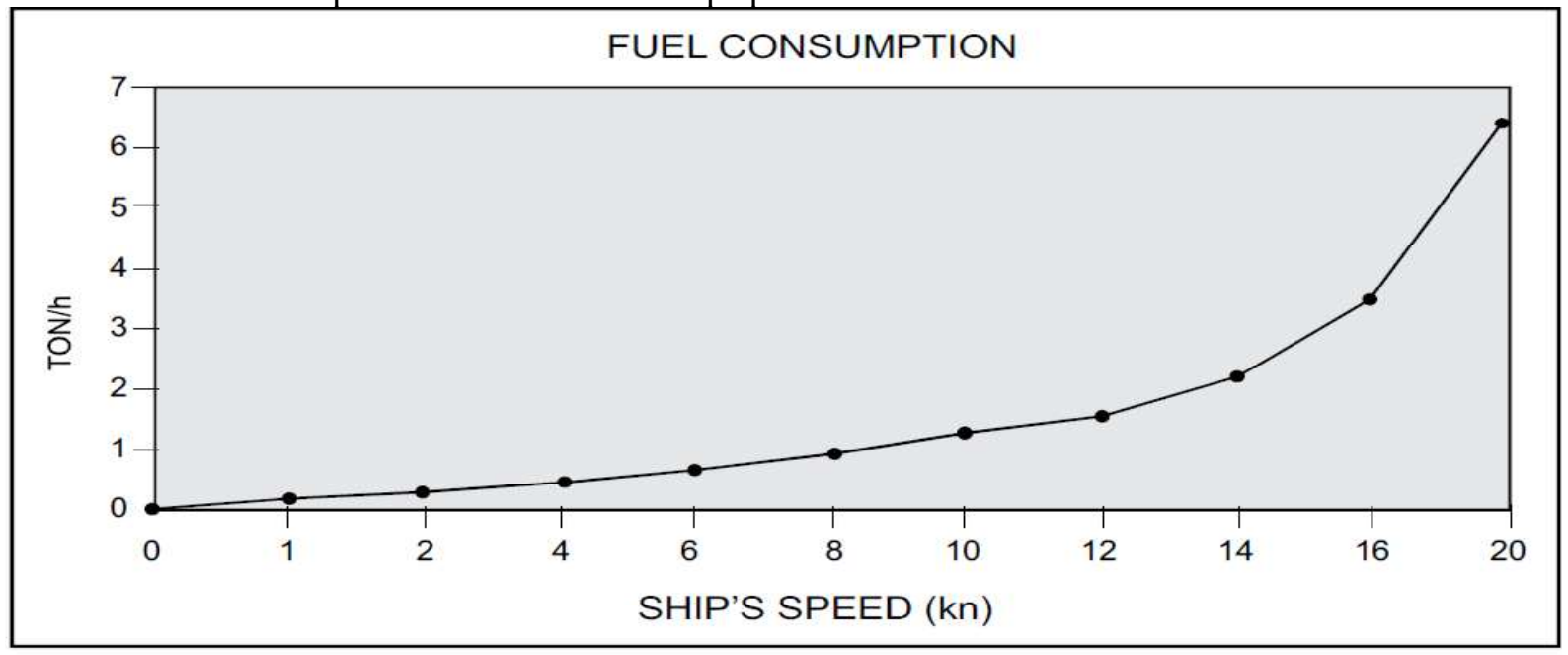

\section{Maintenance of electrical and electronic equipment}

Periodic checks and maintenance are important for the smooth operation of any navigation equipment. This is for maintaining the equipment within optimal performance and operating limits, resulting in the longest service life of the equipment. Regular maintenance is essential for good performance. A regular maintenance schedule must be established and maintained on board by the officer designated for this purpose under the guidance of the Chief Mechanical and with the approval of the ship's commander, especially for equipment considered critical to the safety of the ship. The navigation equipment in the control cabin is all under these rules, by which they are doubled, and if the second equipment (the doublet) fails during navigation, the prompt intervention of the management company is necessary, ensuring thus an efficient communication between the ship, the classification society and the flag company.

The first alarms given by the electrical equipment are due to the physical wear, the action of the passage of time and the external factors. These faults are manifested both at the individual level, at each individual equipment, but also at the level of the connections and modules that make the connection between the equipment. The purpose of the maintenance is to extend the service life of the equipment as well as to increase their average service life, the time between two consecutive repairs. This lifetime is directly reflected in the operating costs of the ship. Better maintenance and proper planning is given by the correct understanding by the watch officer of all aspects related to the operation, management of alarms and the proper application of risk management. This risk management involves the proper management of some equipment or components that are in the set of navigation devices at the time of taking off - the equipment that forms part of the Bridge Integrate System (BIS). [14; 15; 20]

\section{Conclusions}

Navigation equipment is part of the responsibilities and tasks of the officer in the navigation cabin on board ships. The equipment is present in the control cabin of any ship, is of particular importance for the safety of navigation, and according to IMO (International Maritime Organization), their operation must be continuous and under normal operating parameters, according to the manufacturer's specifications. 
A very important step in grouping all the information in one place was achieved by introducing the integrated navigation system (BIS / Bridge Integrate System). This system assists the officer in monitoring the traffic and maneuvering the ship. Also, this integrated navigation system helps the ship's management in making the best decisions. This system also ensures easier communication between the different departments of the ship, between the officers in the engine compartment, and those in the operating compartment of the ship in the control room (loading / unloading) or in the navigation cabin. The system also offers the officer in command of navigation to have complete control over all the equipment of the ship.

The integrated navigation system is designed to have an easy operation, and all the settings that can be adjusted by the user are made according to the needs. These settings create a time extension that allows the officer more time to observe and make decisions when in the navigation command. This is especially possible thanks to Automatic Radar Plotting Aid (ARPA), radar and Electronic Chart Display and Information System (ECDIS) systems that are all integrated into this system.

The watch officer must be aware that equipment such as Automatic Identification System (AIS) and Electronic Chart Display and Information System (ECDIS) are electronic aids that assist him in navigation - the purpose of AIS is to help identify ships, assist in tracking targets. ECDIS and AIS equipment are also useful in search and rescue operations. They simplify the exchange of information (for example, reduce mandatory ship reporting) and can provide additional information to assist with a faster assessment of the situation. These are additional sources of information and should not replace the use of established navigation procedures, such as radar / ARPA -Automatic Radar Plotting Aid and visual surveillance to avoid collision at sea. The use of all electronic equipment does not exempt the officer from liability and from applying the COLREG (International Regulations for Preventing Collisions at Sea) at any time. The watch officer who uses the information provided by the devices at his disposal must be able to make the best decisions regarding the navigational situations.

The energy analysis represents a good complement to the existing methods and practices, and is a structured and systematic way to gather information on the evolution of the ship's energy systems. The energy analysis and management helps to distribute the energy on board the ship, identifies the location of the facilities on board the ship, recognizes the functional blocks in the structure of the Naval Automation Systems (SAN), explains the role of the functional blocks within the SAN, and identifies the components of the functional blocks of the SAN. At the same time, it helps to perform the maneuvers for the control of the ship's automated installations (start / stop / adjustment).

The analysis leads to a better surveillance of the automated naval installations and the equipping of the synoptic naval panels with corresponding electrical and electronic elements of signaling and warning, and it also leads to a better verification of the functioning of the signaling for the naval electrical installations present on the ship's deck in the navigation cabin or anywhere else on the ship. Electricity management leads to: lowering of personnel costs; lower operating costs; streamlining and increasing the efficiency of the processes that take place on board the ship; profit maximization.

Therefore, the idea of having experimental research on the calculation of energy quality indices and on-board equipment is formed. The research regarding the calculation of the quality indices of electricity and of the equipment in the navigation cabin will lead to the development of the methodology that will allow the introduction of new equipment for adapting the ships already in exploitation (with moral wear), to the current needs, so as to respond to the requirements to the new standards imposed by the International Maritime Organization (IMO). 


\section{Bibliografie}

[1] Radu S.,s.a, Particularități ale energiei electrice în sistemul de management energetic pe o navă maritimă;Ed. Muntenia, 2016. p. 17-28.

[2] Albert,H.,Golovanov,N.-Monitorizarea serviciului de alimentare cu energie electric a consumatorilor, Energetica, nr.10,2004

[3] Badea Eugen-Contribuţii la optimizarea proiectării instalaţiilor electrice şi de automatizare Universitarea Tehnică de Construcții Bucureşti, 2010.

[4] Coulouris,G, Dollimore,J.,kindberg,T.,-Distributed systems-Concept and design-Addison Wesley, ISBN 13-97803263544, 2005.

[5] Chalfant,J.S., Chryssostomidis,C.,Angle,M.G.,-Study of parallel AC and DC Electrical Distribution in the all-Electric ship -Proceedings of the Grand Challenges in Modeling and Simulation( GCMS 10), Ottawa, 2011.

[6] Dragomir, E., -Contribuţii la analiza puterilor şi a unor indici de calitate ai funcţionarii sistemelor electroenergetice navale, Teză de doctorat, București, 2008

[7] Dan, F.,--Contribuţii la identificarea, optimizarea și prognoza consumului de energie electrică,Universitatea Oradea, , București, 2008

[8] Samoilescu Gheorghe - Centrale electrice navale-Editura Muntenia,Constanţa ,1999

[9] Chalfant,J.S., Chryssostomidis,C.,-Analysis of various all electric-ship electrical distribution system topologies, IEEE- http://dx.doi.org/10.11.09/ESTS.2011.5770844

[10] * * * - Soluții maritime. Nave comerciale-Schneider Electric

[11] http://www.standard ship test and inspection plan, procedures and data base, U.S.Departament of the Navy Carderock Division, Naval Surface Warface Center, 1999-2017

[12] * * *- http://www.grighthubengineering.com-marine-engines-machinery-73565-ship-controlsystems

[13] * * *- Marine-Siemens-w3.siemens.no/home/no/no/sector/industry/marine/pages/integratedautomation-systems.aspx

[14] Boșneagu, R., Navigația electronică. Navigația ortodromică, Editura Direcției Hidrografice Maritime, Constanța,2013, p 327-393

[15] Bozianu Fr. Echipamente şi sisteme de navigaţie, vol I, Editura Ex Ponto, Constanţa, 2005

[16] ***-Radar and AIS Integrated Bridge Systems vol.1, The Nautical Institut, Londra, 2008

[17] ***- UKHO ALRS NP 282 vol. 2, 2013/2014

[18] OCIMF Safety Bulletin for Inspectors - Sanchi and CF Crystal Collision Incident 2019

[19] https://www.marineinsight.com/marine-navigation/30-types-of-navigational-equipment-andresources-used-onboard-modern-ships - accesat la data de 18 Noembrie 2019.

[20]https://www.researchgate.net/publication/296607800 Electronic Navigation Equipment Electron ic Chart_Display and Information_Systems_in_Greek - accesat la data de 21 Decemberie 2019

[21] http://www.working-the-sails.com/navigation instruments.html - accesat la data de 14 Decembrie 2019

[22]https://www.indiamart.com/nautical-corporation/electronic-navigation-equipments.html - accesat la data 07 Ianuarie 2020

[23]https://www.marineinsight.com/marine-navigation/marine-navigation-systems-and-electronictools-used-by-ships-pilot/ accesat la data de 12 Ianuarie 2020

[24] https://www.mardep.gov.hk/en/msnote/pdf/msin1647anx1.pdf - accesat la 10 Ianuarie 2020

[25] https://www.libramar.net/news/understanding_gmdss/2018-11-07-3918 - accesat la 14 Noembrie 2019

[26] https://www.libramar.net/news/the adlard coles book of radar/2018-04-29-3659 -accesat la 18 Noembrie 2019 